\title{
Historia epistolar para no dormir: Uruguay contra Ana (para obligarle a hacerse la mamografía "preventiva")
}

História epistolar para não dormir: Uruguai contra Ana (para obrigá-la a fazer mamografia "preventiva")

An epistolary story for not sleeping: Uruguay against Ana (to compel her to undergo "preventive" mammography)

Juan Gérvas. Médico general, Equipo CESCA, Doctor en Medicina, profesor honorario de salud pública Universidad Autónoma de Madrid, profesor invitado de salud internacional, Escuela Nacional de Sanidad. Madrid, España. jjgervas@gmail.com (Autor correspondiente)

En noviembre de 2012 estábamos (mi esposa, Mercedes Pérez Fernández, y yo) en Argentina, en La Pampa profunda, a cargo de los dos nietos que tenemos allí. Nuestros hijos se habían ido de viaje para celebrar los diez años de matrimonio. Pasábamos el día yendo y volviendo a la escuela, haciendo compras ocasionales, arreglando la casa, cuidando los perros, las ovejas y otro ganado menor, y atendiendo el jardín y la piscina. El nieto más pequeño tenía entonces 3 ańos, la nieta mayor cumplió los 7 ańos el 11 de noviembre, y lo celebramos adecuadamente. De vez en cuando tenía tiempo para ponerme al día con el correo electrónico. El 17 de noviembre recibí uno desde Uruguay, que no pude creer. Alguien que no conocía de nada escribía literalmente:

\section{"Estimado Dr. Juan Gérvas,}

Llegué a Ud. navegando la web en busca de material en contra del cribado para la detección precoz de cáncer de mama usando la mamografía como técnica de diagnóstico. Resulta que en mi país (Uruguay) para poder trabajar hay que tramitar el carnet de salud. Tiene un protocolo complejo según género y edad. En particular para las mujeres entre 40 y 59 años de edad (yo tengo 51) dispone que deben hacerse una mamografía cada 2 años. Esto es asi desde el 2006 por un decreto del ex presidente Dr. Tabaré Vázquez. El Dr. Vázquez era (mientras fue presidente de 2005 a 2010) y es en la actualidad médico oncólogo y propietario de una clínica que proporciona tanto servicios de mamografía como de radioterapia. Debido a todo lo que lei sobre la alta tasa de sobrediagnósticos, sobretratamientos y mutilaciones innecesarias que resultan de tal cribado, es que estoy luchando en forma totalmente individual para que las autoridades públicas me exoneren de tal obligación. También descubri que en el mundo desarrollado (Europa, EEUUy Canadá) para participar en programas de cribado por mamografia, a la mujer se le requiere el consentimiento informado. Sé que hay una gran polémica en torno a la información que se le brinda a la mujer, es decir, si se le explican los riesgos y daños junto con los beneficios. Lo molesto por si Ud puede facilitarme alguna información que no he encontrado.
Palabras clave:

Programas Obligatorios Coerción

Bioética

Medicalización

Autonomía Personal

Palavras-chave: Programas Obrigatórios Coerção Bioética Medicalização Autonomia Pessoal

\section{Keywords:}

Mandatory Programs

Coercion

Bioethics

Medicalization

Personal Autonomy 
Primero me interesa conocer la norma europea que exige el consentimiento informado de la mujer que participa en un programa de cribado para la detección precoz del cáncer de mama con mamografía. Si Ud me puede facilitar un link o cualquier pista por la cual googlear, le quedaría muy agradecida. Segundo me interesa saber si han prosperado demandas judiciales iniciadas por mujeres que sometidas al cribado por mamografía hayan sufrido daños, entre otros, "cáncer por acumulación de la radiación recibida". Estoy convencida que desde el punto de vista de los expertos en control de calidad, la mamografía aplicada en mujeres asintomáticas constituye un *ensayo destructivo*, que a la larga demuestra que la mamografía provoca lo que pretende detectar porque introduce un factor (radiación) que de sobra se sabe puede desarrollar cáncer. Y como supongo que los patólogos no tienen forma de distinguir un cáncer provocado por radiación de uno desarrollado espontáneamente, es que me animo a pensar que alguna mujer luego de someterse a " $"$ " mamografias con resultado negativo, si la " $n+1$ " es positiva, lejos de pensar que le detectaron precozmente el cáncer, bien podría encontrar un abogado que la defendiera acusando a los promotores del asunto, de haberle provocado lo que pretendian evitar. Desde ya le agradezco la atención a estas líneas.

Quedando a la espera de noticias suyas, le saluda muy atentamente,

Ing. Ana Rosengurtt"

Dediqué unas horas nocturnas a comprobar la veracidad de la queja de Ana. También tomé contacto con los organizadores del Seminario que íbamos a celebrar en Montevideo (Uruguay), el 1 de diciembre, con Miguel Pizzanelli. Y, a través de la Escuela Nacional de Sanidad de Madrid (España), con el Ministerio de Salud de Uruguay. Además, puse en circulación en la Red lo que había encontrado al respecto. Al día siguiente, 18 de noviembre de 2012, escribí a Ana:

"Estimada Ana:

Le contesto desde este correo-e [el de mi esposa, de Google] pues mi correo-e habitual no funciona bien desde el extranjero, y estamos en Argentina (en La Pampa, al cuidado de los nietos de "acá").

Gracias por su confianza. Para serle sincero he tenido que cercionarme por mi mismo de lo que decía pues me resultó increíble leerlo. Que yo sepa no hay pais en el mundo en el que se haya llegado a ese extremo de "salud persecutoria".

Es lástima que no haya participado en el Seminario en Buenos Aires, sobre medicalización [el 29 de octubre], pues le habría venido bien. Daré un Seminario en Montevideo, el sábado 1 de diciembre, pero sobre "Sistemas de salud basados en atención primaria".

En el mundo desarrollado no cabe la menor duda de que se precisa el consentimiento informado para realizar la mamografía. A nadie se le ha ocurrido tener que legislar sobre ello, como no se legisla sobre "comer niños fritos" pues es algo inconcebible. Hay un movimiento mundial de mejora de la información a la mujer. Entre en el Centro Cochrane de Copenhague (Dinamarca). O en el Servicio de Medicina Preventiva de Asturias (España).

En la página www.equipocesca.org tiene muchisima información sobre la mamografia

http://www.equipocesca.org/organizacion-de-servicios/irrelevante-efecto-del-cribado-sobre-el-riesgo-de-morir-por-cancer-de-mamala-mamografia-no-salva-ni-prolonga-vidas/

http://www.equipocesca.org/uso-apropiado-de-recursos/modos-de-ver-falta-de-efectividad-del-cribado-con-mamografia-del-cancerde-mama-datos-metodos-y-resultados-sesgados-en-un-innovador-diseno-poblacional-sobre-cribado-2l

http://www.equipocesca.org/organizacion-de-servicios/de-la-investigacion-a-la-toma-de-decisiones-interpretaciones-sobre-el-ensayodel-cribado-del-cancer-de-mama-swedish-twi-county/

Respecto a la segunda pregunta, la inducción de cáncer de mama por la mamografía es efecto secundario menor (mayor si se tienen mutaciones del gen BRCA y otros). Su mejor defensa son los textos del Centro Cochrane de Copenhaguen (incluso en español), los de Welch sobre "overdiagnosis" y los nuestros. Niéguese y busque apoyo en grupos como los que organizan el Seminario del sábado 1 de diciembre, que están sensibilizados sobre medicalización y excesos de la prevención.

Abajo copio lo que acabo de difundir en listas electrónicas de España, Brasil, Argentina y Uruguay, y en Twitter (@ JuanGrvs) y en Facebook y en Linkedin. Esa legislación uruguaya hay que eliminarla, es una lacra mundial, "Sana Inquisición".

Reciba un saludo de

Juan Gérvas 
1.Uruguay, Salud persecutoria estatal. Carnet de salud obligatorio mujeres. Cada 2 años mamografía, Papanicolau. De 40 a 60 años. Imprescindible para trabajar. El Presidente que firma el decreto, médico oncólogo con práctica en radioterapia http://www.elderechodigital.com.uy/smu/legisla/D0600571.html

2. Uruguay. Obligatorio revisión médica y dental, orina, colesterol, hemograma, glicemia, screening mamógrafico, y PAP cada dos años.

La realidad supera a la ficción

http://www.scielo.br/scielo.php?script=sci_arttext\&pid=S0034-89102007000300019

http://www.elsevier.es/sites/default/files/elsevier/eop/S0213-9111(11)00100-2.pdf

En fin.

Nueva Laputa

http://www.actasanitaria.com/opinion/el-mirador/articulo-quien-tema-el-colesterol-laputa.html

¿Qué habrán hecho los uruguayos para merecer este encarnizamiento?

Un saludo

Juan Gérvas

Desde entonces hasta finales de enero de 2014 he intercambiado más de 100 correos electrónicos con Ana (para aconsejar, documentar y acompañarla en su queja judicial, "gratis et amore"). Ana ya había contactado con Peter Gotzsche, del Centro Cochrane de Copenhague, quien me cedió la antorcha. Volví de Montevideo a Madrid el 3 de diciembre de 2012, después de haber hablado con personal del Ministerio de Salud Pública de Uruguay, con la promesa de que el asunto se arreglaría. Pero como el caso no progresaba, Miguel Pizzanelli publicó un comentario en su bitácora (blog) "Están cambiando los tiempos", el 21 de febrero de 2013, reclamando el cambio en la legislación: http://estancambiandolostiempos.blogspot. com.es/2013/02/cribado-cancer-de-mama-un-poco-mas-de.html

Por ese motivo organicé, en inglés, una campaña internacional de denuncia de la situación en Uruguay, incluyendo el grupo "BMJ editorial advisers for primary care", al que pertenezco. Efectivamente, el asunto interesó al British Medical Journal y a Sophie Arie, una periodista del mismo, que nos entrevistó: a Ana, a Miguel Pizzanelli y a mí. Con todo ello escribió un texto, que se publicó el 21 de marzo de 2013, titulado: "Uruguay's mandatory breast cancer screening for working women aged 40-59 is challenged” http://www.bmj.com/content/346/bmj.f1907

Desde entonces, las cosas no han ido demasiado bien para Ana, aunque por ahora no ha perdido el trabajo ni ningún juicio. No le ha faltado el apoyo de Miguel Pizzanelli y de la Sociedad Uruguaya de Medicina de Familia y Comunitaria, pero, está en marcha, en Uruguay, un proyecto legislativo de endurecimiento de las exigencias "preventivas" del "carnet de salud", con mamografía anual.

Ana creó el 5 de marzo de 2013 una petición en Avaaz.org dirigida a la Ministra de Salud Pública de Uruguay: https:// secure.avaaz.org/es/petition/MAMOGRAFIA_OBLIGATORIA_EN_URUGUAY_UN_PROBLEMA_CIENTIFICO_Y_ UN_ABUSO_ETICO/

Ana ha publicado en varios medios generalistas uruguayos, con apoyo diverso y el pleno rechazo de dos médicos especialistas. El 16 de septiembre de 2013 dediqué un "El Mirador" a esta cuestión con el título de "Uruguay, presidente excepcional y dictadura preventiva institucional" http://www.actasanitaria.com/uruguay-presidente-excepcional-y-dictadurapreventiva institucional/

A través de la Red, Ana tomó contacto con Hazel Thornton, quien publicó una carta en el British Medical Journal el 21 de enero de 2014, titulada: "Bringing an end to mandatory breast cancer screening in Uruguay" http://www.bmj.com/ content/348/bmj.g390

La cuestión que plantea Ana se refiere a la práctica y a la ética médica y también a los derechos humanos. Es, sin más, una discriminación intolerable y, como tal, terminará en la Organización de las Naciones Unidas.

NOTA: Ana Rosengurtt ha leído y aprueba este texto, incluyendo el que conste su nombre. Para saber más sobre ella y su lucha contra la mamografía obligatoria en Uruguay visite el siguiente enlace: http://www.actasanitaria.com/la-lucha-contra-las-mamografiasobligatorias-y-por-los-derechos-humanos-ana-rosengurtt-de-urugua/ 